\title{
Application Research of Big Data Technology in Audit Field
}

\author{
Guanfang Qiao \\ WUYIGE Certified Public Accountants LLP, Wuhan, China \\ Email:430060mlbsabc@sina.com
}

How to cite this paper: Qiao, G. F. (2020) Application Research of Big Data Technology in Audit Field. Theoretical Economics Letters, 10, 1093-1102.

https://doi.org/10.4236/tel.2020.105064

Received: September 4, 2020

Accepted: October 13, 2020

Published: October 16, 2020

Copyright ( 2020 by author(s) and Scientific Research Publishing Inc. This work is licensed under the Creative Commons Attribution International License (CC BY 4.0).

http://creativecommons.org/licenses/by/4.0/

\begin{abstract}
The era of big data has brought great changes to various industries, and the innovative application effect of big data-related technologies also shows obvious advantages. The introduction and application of big data technology in the audit field also become the future development trend. Compared with the traditional mode of audit work, the application of big data technology can help to achieve more ideal results, which needs to promote the adaptive transformation and adjustment of audit work. This paper makes a brief analysis of the application of big data technology in audit field, which first introduces the characteristics of big data and its technical application, and then points out the new requirements for audit work in the era of big data, and finally discusses how to apply the big data technology in the audit field, hoping that it can be used for reference.
\end{abstract}

\section{Keywords}

Big Data, Technology, Audit, Application

\section{Introduction}

With the rapid development of information technology in today's world, the amount of data information is getting larger and larger, which presents the characteristics of big data. Big data refers to a collection of data that cannot be captured, managed and processed by conventional software tools within a certain time. It is a massive, high-growth, diversified information asset that requires new processing models to have greater decision-making power, insight and process optimization capabilities. Under the background of big data development era, all walks of life should actively adapt to it in order to form a more positive change. With the development of new social economy, audit work is faced with higher requirements. The traditional audit methods and concepts have been 
difficult to show good adaptability, and it is very easy to appear many problems and defects. So positive changes should be made, and proper and scientific integration of big data technology is an effective measurement, which deserves high attention. Of course, the application of big data technology in the field of audit is indeed facing higher difficulties, for example, the development of audit software and the establishment of audit analysis model need to be effectively adjusted from multiple levels in order to give full play to the application value of big data technology.

\section{Overview of Big Data Technology}

Big data technology is a related technical means emerging with the development of big data era. It mainly involves big data platform, big data index system and other related technologies, and has been well applied in many fields. Big data refers to massive data, and the corresponding information data cannot be intuitively observed and used. It is faced with high difficulties in data information acquisition, storage, analysis and application, and inevitably shows strong application significance, and has become an important content that attracts more attention under the development of the current information age. From the point of view of big data itself, in addition to the obvious characteristics of large amount, it is often characterized by obvious diversity, rapidity, complexity and low value density. Therefore, it is inevitable to bring great difficulty to the application of these massive data, and it puts forward higher requirements for the application of big data technology, which needs to be paid high attention to (Ingrams, 2019).

Based on the development of the era of big data, the core is not to obtain massive data information, but how to conduct professional analysis and processing for these massive information, so as to play its due role and value. In this way, it is necessary to strengthen the research on big data technology, so that all fields can realize the optimization analysis and processing of massive data information with the assistance of big data technology, and meet the original application requirements. In terms of the development and application of current big data technologies, data mining technology, massively parallel processing database, distributed database, extensible storage system and cloud computing technology are commonly used. These big data technologies can be effectively applied to the massive information acquisition, storage, analysis and management.

Big data has ushered in a major era of transformation, which has changed our lives, work and even our thinking. More and more industries maintain a very optimistic attitude towards the application of big data, and more and more users are trying or considering how to use similar big data to solve the problem, so as to improve their business level. With the gradual advance of digitization, big data will become the fourth strategy that enterprises can choose after the three traditional competitive strategies of cost leadership, differentiation and concentration. 


\section{Requirements on Auditing in the Era of Big Data}

\subsection{Change Audit Objectives}

In the era of big data development, in order to better realize the flexible application of big data technology in the auditing field, it is necessary to pay high attention to the characteristics of the era of big data development, and it requires adaptive transformation so as to create good conditions for the application of big data technology. With the development of big data era, the audit work should first pay attention to the effective transformation of its own audit objectives, and it is necessary to gradually broaden the tasks of audit work in order to improve the value of audit work and give play to the application value of big data technology. In addition to find all kinds of abnormal clues in the target and control the illegal behaviors, audit work also needs to take into account promoting the development of the target, which requires the realization of the optimization assistance for relevant operating systems, and to play an active role in risk assessment and benefit improvement, better explore the law of development, and then give play to the reference value in decision analysis (Gepp, 2018).

\subsection{Change Audit Content}

With the development of big data era, the development and transformation of audit field also need to focus on the specific audit content. The change of audit content is also the basic requirement of applying big data technology. It is necessary to select appropriate big data technology centering on audit content. Under the background of big data, audit work is often faced with more complicated content, which involves not only the previously simple data information such as amount and various expenses, but also more complicated text information, audio information and video information. As the content is more abundant, it will inevitably increase the difficulty of analysis and processing, which puts forward higher requirements for the application of big data technology. Of course, this also requires the collection of rich and detailed massive data information as much as possible in the future audit work, so as to better complete the audit task and achieve the audit objectives mentioned above with the assistance of big data technology (Alles, 2016).

\subsection{Change Audit Thinking}

Under the background of development of big data era, the development of audit field should also focus on the change of thinking, which is also the key premise to enable audit staff to actively adapt to the new situation. Only by ensuring that audit staff have new audit thinking, can they flexibly apply big data technology, optimize and deal with rich practical contents in the era of big data, and finally better enhance the audit value. Specifically, the change in audit thinking is mainly reflected in the following aspects: First of all, audit staff needs to change the previous sampling audit thinking and realize a comprehensive audit, carry 
out a comprehensive audit analysis for all the information to avoid any omission. Secondly, the requirements of precision should be gradually reduced in the process of audit (Shukla, 2019). Because with the application of big data, its information value density is relatively low, which is likely to affect the accuracy of data, so it needs to be optimized with the help of appropriate big data technology. In addition, the change of audit thinking also needs to change from the original causal relationship to the correlation relationship, which requires that emphasis should be placed on exploring the correlation between different factors and indicators, so as to provide reference for decision-making and other work.

\subsection{Change Audit Techniques}

With the development of big data era, the transformation of audit field needs to be embodied in the technical level. Because audit content is more complex and involves a large number of types, so it is inevitable that the traditional audit technology cannot form a good satisfactory effect, thus we need to focus on innovation and optimization of the technical means. Based on the higher requirements of audit work under this new situation, the following conditions should be met in the application of correlation analysis technology. First of all, the application of audit technology should be suitable for the analysis and processing of complex data, requiring it to be able to carry out comprehensive analysis of a variety of different types of data information, so as to avoid the improper analysis technology. Secondly, the application of audit technology should also show the characteristics of intuition, try to use visual analysis means, to promote the audit results can be presented more ideal, for reference and application. In addition, in the era of big data, the application of technologies related to audit work often needs to pay attention to data mining, which requires mining valuable clues from massive data information and significantly improving the speed of data mining and analysis to meet the characteristics of big data.

\section{Application of Big Data Technology in Audit Field}

\subsection{Data Mining Analysis}

The application of big data technology in the audit field should focus on data mining analysis, which is obviously different from the data verification analysis under the traditional audit mode, and can better realize the efficient application of data information. In the previous audit work, random sampling was usually conducted on the collected financial data and information, and then the samples were checked and proofread one by one to verify whether there were obvious abnormal problems, which mainly involved query analysis, multi-dimensional analysis and other means. However, with the application of big data technology, data warehouse, data mining, prediction and analysis and other means can be better used to realize the comprehensive analysis and processing of massive data information, in order to better explore the laws of corresponding data informa- 
tion (Harris, 2020). The commonly used methods include classification analysis, correlation analysis, cluster analysis and sequence analysis. Based on the transformation of data analysis brought by big data technology application, the value of the audit work can be further promoted. It is no longer confined to the problem verification, but tries to explore more relationship between data. It enables these data information to play a stronger application value based on the found multiple correlation, and avoid the waste of data information (Sookhak, 2017). For example, in the financial loan audit, such data mining analysis technology can be fully utilized to realize the classification analysis of all data information in the loan, so as to better identify the difference between non-performing loans and normal loans, and provide reference for the follow-up loan business.

\subsection{Real-Time Risk Warning}

The application of big data technology in the field of audit also has the effect of risk prevention, which is more convenient and efficient to analyze and identify possible risk factors, so as to give timely warning, avoid the risk problems leading to major accidents, and realize the control of economic losses. This is also obviously better than the traditional audit work mode. In the past, audit work often only found problems and gave feedback to some clues of violation, but it was difficult to realize risk warning. In the application of big data technology, the characteristics of sustainability are usually reflected. It can dynamically analyze and process the constantly rich and updated data, so that it can continuously monitor and dynamically grasp the change status of the audit target, then give timely feedback and early warning to the abnormal problems so as to remind the relevant personnel to take appropriate measures to prevent the problems. Therefore, the follow-up audit in the future audit field needs to be gradually promoted, so as to better realize the optimization of audit work with the help of big data technology. In the application of following-up audit mode, higher requirements are usually put forwards for the data analysis platform, which need to pay attention to technical innovation, establishing comprehensive audit data analysis platform and utilizing the means such as the Internet and information, to create favorable conditions for big data technology application and avoid the hidden problems in data collection. In carrying out the land tax audit work, for example, the application value of the follow-up audit mode is outstanding. The relevant staff often require full access to huge amounts of data on the provincial land tax information, reflect the characteristic of linkage, and update the corresponding data in real time, then they can analyze follow-up audit and timely require some abnormal problems so as to take timely warning to solve these problems.

\subsection{Multi-Domain Data Fusion}

Of course, in order to better play the application value of big data technology in the audit field, it is necessary to pay attention to the extensive collection and 
sorting of data information, which requires to make comprehensive analysis and judgment from multiple angles as far as possible to avoid the impact of incomplete data and information on the analysis effect. With the application of big data technology, audit work often involves the cross-analysis and application of multiple different database information, thus posing higher challenges to big data technology. It is necessary to ensure that it has cross-database analysis ability, and can use appropriate and reasonable analysis tools to better analyze and identify possible abnormal problems. Therefore, it is necessary to pay attention to the fusion and application of multi-domain data, which requires the comprehensive processing of multiple databases, so as to obtain richer and more detailed analysis results and play a stronger role in subsequent applications. For example, in order to analyze and clarify China's macroeconomic and social risks, it is often necessary to comprehensively analyze government debt audit data, macroeconomic operation data, social security data and financial industry data, etc., so as to obtain more accurate results and conduct early risk warning. In the economic responsibility audit, it puts forward higher requirements for data fusion in multiple fields, and needs to obtain corresponding data information from finance, social security, industry and commerce, housing management, tax, public security and education, then integrate the data information effectively, and define the economic responsibility by means of horizontal correlation analysis and vertical comparison analysis in order to optimize the adjustment (Xiao, 2020).

\subsection{Build a Large Audit Team}

The application of big data technology in audit field is not only the innovation transformation at the technical level, but also the transformation from multiple perspectives such as organizational mode and personnel structure, so as to better adapt to this new situation and avoid serious defects in audit work. For example, in view of the obvious isolated phenomenon in the previous audit work, although the simple audit conducted by each department as a unit can find some problems, it is difficult to form a more comprehensive and detailed audit effect. The audit value is obviously limited and needs to be innovated and adjusted by big data technology. Based on this, the construction of large audit group has become an important application mode. The future audit work should rely on the large audit group to divide the organizational structure from different functions such as leadership decision-making, data analysis and problem verification, so as to realize the orderly promotion of the follow-up audit work. For example, the establishment of a leading group could facilitate the implementation of the audit plan, to achieve leadership decisions for the entire audit work. For the analysis of massive data information, the data analysis group is required to make full analysis of the target with the help of rich and diverse big data technologies, so as to find clues and problems and explore rules and relationships. However, the clues and rules discovered need to be further analyzed by the problem verification team and verified in combination with the actual situation, so as to complete the 
audit task (Castka et al., 2020).

The application of this large audit team mode can give full play to the application value of big data technology, avoid the interference brought by organizational factors, and become an important trend of optimization development in the audit field in the future. Of course, in order to give full play to the application value of the large audit team, it is often necessary to focus on the optimization of specific audit staff to ensure that all audit staff have a higher level of competence. Audit staff not only need to master and apply big data-related technical means, but also need to have big data thinking, realize the transformation under this new situation, and avoid obstacles brought by human problems. Based on this, it is of great importance to provide necessary education and training for audit staff, which should carry out detailed explanation around big data concept, technology and new audit mode, so as to make them better adapt to the new situation

\subsection{Data Analysis Model and Audit Software Development}

In the current development of audit field, as an important development trend, the application of big data technology does show obvious advantages in many aspects, and also can play good functions. However, due to the complex audit work, the application of big data technology is bound to have the characteristics of keeping pace with the times and being targeted, so as to better improve its service value. Based on this, the application of big data technology in future audit work should focus on the development of data analysis model and audit professional software, so as to create good application conditions for the application of big data technology. First of all, in-depth and comprehensive analysis in the audit field requires a comprehensive grasp of all audit objectives and tasks involved in the audit industry, so as to purposefully develop the corresponding data analysis model and special software, and promote its application in subsequent audit work more efficient and convenient. For example, the query analysis, mining analysis and multi-dimensional analysis involved in the audit work need to be matched with the corresponding data analysis model in order to better improve the audit execution effect. In the development and application of audit software, it is necessary to take into account the various functions. For example, in addition to discovering and clarifying the defects existing in the audit objectives, it is also necessary to reflect the risk warning function, so as to better realize the audit function and highlight the application effect of big data technology.

\subsection{Cloud Audit}

The application of big data technology in the auditing field is also developing towards cloud auditing, which is one of the important manifestations of the development of big data era. From the application of big data related technologies, it is often closely related to cloud computing, and they are often difficult to be 
separated. In order to better use big data technology, it is necessary to rely on cloud computing mode to better realize distributed processing, cloud storage and virtualization processing, facilitate the efficient use of massive data information, and solve the problem of data information. Based on this, the application of big data technology in audit field should also pay attention to the construction of cloud audit platform in the future, to better realize the optimization and implementation of audit work. In the construction of cloud audit, it is necessary to make full use of big data technology, intelligent technology, Internet technology and information means to realize the orderly storage and analysis and application of massive data information, and at the same time pay attention to the orderly sharing of massive data information, so as to better enhance its application value. For example, for the comprehensive analysis of the above mentioned cross-database data information, cloud audit platform can be used to optimize the processing. The overall analysis and processing efficiency is higher, which can effectively meet the development trend of the increasing difficulty of the current audit. Of course, the application of cloud audit mode can also realize the remote storage and analysis of data information, which obviously improves the convenience of audit work, breaks the limitation of original audit work on location, and makes the data sharing effect of relevant organizations stronger, thus solving the problem of isolated information (Appelbaum, 2018).

\section{Risk Analysis of Big Data Audit}

Although big data audit plays an important role in improving the audit working mode and improving the audit working efficiency, there are still some risks in the use of data acquisition management that need to be paid attention to:

\subsection{Data Acquisition and Collation Risks}

Data acquisition risks are mainly reflected in two aspects: On the one hand, there is a lack of effective means to verify the data of the auditee, and the integrity and authenticity of the data cannot be guaranteed, which can only be verified through the later extended investigation. On the other hand, the quality of collected data is not good, and a large number of invalid data will seriously affect the quality of data analysis. In addition, data collected outside the auditees, such as network media and social networking sites, also have high data risks. In terms of data collation, many audit institutions have collected data from a number of industries, but the data standards and formats of each industry are not same. Even within the same industry, the data formats used by organizations vary widely. In the absence of a unified audit data standard table, the data collation is difficult, and the multi-domain data association analysis method is still difficult in the practical application process.

\subsection{Data Analysis and Usage Risks}

The risk of data analysis is mainly reflected in the analytical thinking and me- 
thods of auditors. When auditors are not familiar with the business and have weak data modeling ability, they are likely to make logic errors in the actual analysis, resulting in the deviation of data analysis results. In terms of data usage, due to the influence of factors such as data authenticity, integrity and logical association of data tables, the data analysis results are often greatly deviated from the actual situation. If direct use the data analysis results, there is a greater risk, so auditors need to be cautious.

\subsection{Data Management Risk}

Data management risks are mainly manifested as data loss, disclosure and destruction in the process of storage and transmission. The data collected during auditing involves information of many industries. The loss and disclosure of data will cause great losses to relevant units, and at the same time, it will also have a negative impact on the authority and credibility of audit institutions. Among them, the most important data management risk is the management of data storage equipment, such as loss of auditors' computers and mobile storage media, weak disaster prevention ability of computer room equipment, insufficient data network encryption, etc., which should be the key areas of attention to prevent data management risk.

\section{Conclusion}

In a word, the introduction and application of big data technology has become an important development trend in the current innovative development of audit field in China. With the introduction and application of big data, audit work does show obvious advantages with more prominent functions. Therefore, it is necessary to explore the integration of big data technology in the audit field from multiple perspectives in the future, and strive to innovate and optimize the audit concept, organizational structure, auditors and specific technologies in order to create good conditions for the application of big data technology. This paper mainly discusses the transformation of big data technology to the traditional audit work mode and its specific application. However, as the application of big data in the field of audit is not long, the research is inevitably shallow. With the development of global economic integration, multi-directional and multi-field data fusion will make audit work more complex, so big data audit will be normalized and provide better reference for decision-making.

\section{Conflicts of Interest}

The author declares no conflicts of interest regarding the publication of this paper.

\section{References}

Alles, M., \& Gray, G. L. (2016). Incorporating Big Data in Audits: Identifying Inhibitors and a Research Agenda to Address Those Inhibitors. International Journal of Ac- 
counting Information Systems, 22, 44-59. https://doi.org/10.1016/j.accinf.2016.07.004

Appelbaum, D. A., Kogan, A., \& Vasarhelyi, M. A. (2018). Analytical Procedures in External Auditing: A Comprehensive Literature Survey and Framework for External Audit Analytics. Journal of Accounting Literature, 40, 83-101.

https://doi.org/10.1016/j.acclit.2018.01.001

Castka, P., Searcy, C., \& Mohr, J. (2020). Technology-Enhanced Auditing: Improving Veracity and Timeliness in Social and Environmental Audits of Supply Chains. Journal of Cleaner Production, 258, Article ID: 120773.

https://doi.org/10.1016/j.jclepro.2020.120773

Gepp, A., Linnenluecke, M. K., O’Neill, T. J., \& Smith, T. (2018). Big Data Techniques in Auditing Research and Practice: Current Trends and Future Opportunities. Journal of Accounting Literature, 40, 102-115. https://doi.org/10.1016/j.acclit.2017.05.003

Harris, M. K., \& Williams, L. T. (2020). Audit Quality Indicators: Perspectives from Non-Big Four Audit Firms and Small Company Audit Committees. Advances in Accounting, 50, Article ID: 100485. https://doi.org/10.1016/j.adiac.2020.100485

Ingrams, A. (2019). Public Values in the Age of Big Data: A Public Information Perspective. Policy \& Internet, 11, 128-148. https://doi.org/10.1002/poi3.193

Shukla, M., \& Mattar, L. (2019). Next Generation Smart Sustainable Auditing Systems Using Big Data Analytics: Understanding the Interaction of Critical Barriers. Computers \& Industrial Engineering, 128, 1015-1026. https://doi.org/10.1016/j.cie.2018.04.055

Sookhak, M., Gani, A., Khan, M. K., \& Buyya, R. (2017). WITHDRAWN: Dynamic Remote Data Auditing for Securing Big Data Storage in Cloud Computing. Information Sciences, 380, 101-116. https://doi.org/10.1016/j.ins.2015.09.004

Xiao, T. S., Geng, C. X., \& Yuan, C. (2020). How Audit Effort Affects Audit Quality: An Audit Process and Audit Output Perspective. China Journal of Accounting Research, 13, 109-127. https://doi.org/10.1016/j.cjar.2020.02.002 